\title{
Neuropsychiatric aspects in a rare case of hypothalamic obesity
}

Mareike R. Stieg ${ }^{1}$, Matthias K. Auer ${ }^{1}$, M. Buchfelder ${ }^{2}$, G. K. Stalla ${ }^{1}$

${ }^{1}$ Max-Planck-Institute f. Psychiatry, Munich, ${ }^{2}$ Departement of Neurosurgery, University of Erlangen

Case report: A 22-year-old woman presented with weight gain (class I obesity), oligomenorrhoea, impaired vision and altered concentration. MRI diagnostic revealed a suprasellar tumor ( $35 \times 25 \times 20 \mathrm{~mm}$ ).

With suspected craniopharyngeoma she was treated with transcranial surgery; in fact a suprasellar haemangioma could be removed partially.

Only five cases of cavernous malformations of the hypothalamus have been described in literature so far. ${ }^{1}$

The patient suffered from tachycardia, anhidrosis and an alteration in temperature regulation with basal temperature between $38,0-38,3 \mathrm{C}$ and rise up to $40 \mathrm{C}$ during light exercise.
Suppression of sympathic nervous system

She revealed complete pituitary deficiency with concomitant hyperprolactinemia and secondary amenorrhoea.

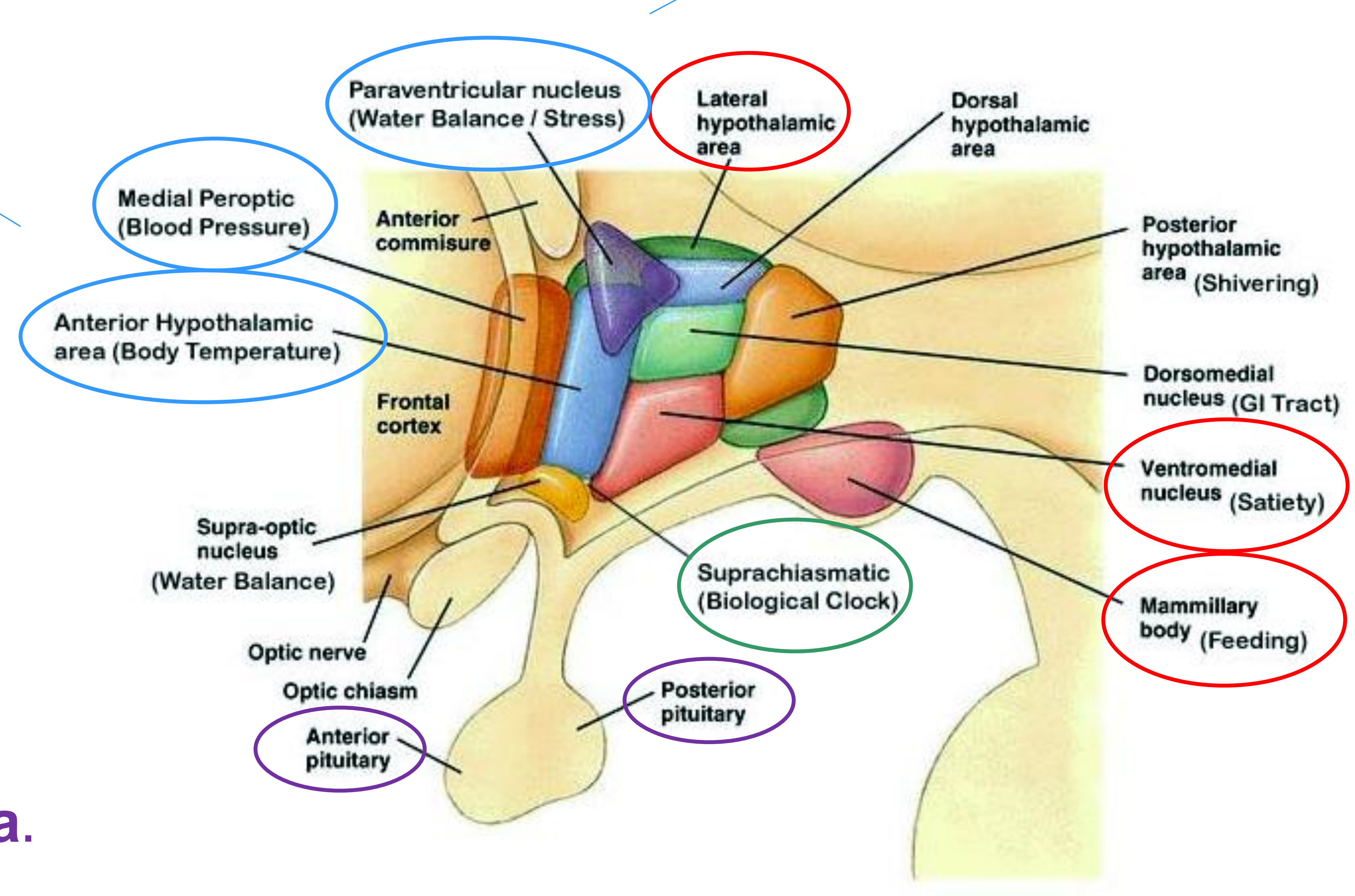

She revealed distinct hyperinsulinemia and developed type II diabetes mellitus.

She still presented with alteration in appetite with hyperphagia and excessive weight gain up to class III obesity.

The patient suffered from alteration in sleep-wake cycle with increased daytime sleepiness.

Neuropsychological functioning indicated affective disorder with loss of motivation, alteration in cognition, learning and memory processes.

Increased prevalence of affective and social dysfunctions in patients treated for childhood craniopharyngeoma. ${ }^{2}$

$>$ Association of neuropsychiatric aspects with degree of damage to frontal lobe due to tumour size, localization and transcranial surgery. ${ }^{3}$

\section{Therapy approach?}

$>$ Treatment with somatostatin analog (Octreotide15 $\mu \mathrm{g} / \mathrm{kg} / \mathrm{d}$ for six months) can reduce hyperinsulinemia, decrease caloric intake and improve quality of life. ${ }^{4}$

$>$ Melatonin treatment $(6 \mathrm{mg} / \mathrm{d})$ improves daytime sleepiness and increases activity. ${ }^{5}$

${ }^{1}$ Liu et al. Cavernous malformations of the optic pathway and hypothalamus: analysis of 65 cases in the literature, 2010

2 Zada et al. Prevalence of Neurobehavioural, Social and Emotional Dysfunction in Patients Treated for Childhood Craniopharyngeoma: A Systematic Literature Review, 2013

${ }^{3}$ Bawden et al. Neuropsychological functioning following craniopharyngioma removal, 2009

${ }^{4}$ Lustig et al. Octreotide therapy of pediatric hypothalamic obesity: a double-blind, placebo-controlled trial, 2003

${ }^{5}$ Müller et al. Melatonin treatment in obese children with childhood craniopharyngeoma and increased daytime sleepiness, 2006 